\title{
The far-lateral approach: destruction of the condyle does not necessarily result in clinically evident craniovertebral junction instability
}

\author{
Ehab Shiban, MD, Elisabeth Török, MD, Maria Wostrack, MD, Bernhard Meyer, MD, and \\ Jens Lehmberg, MD
}

Department of Neurosurgery, Klinikum rechts der Isar, Technische Universität München, Munich, Germany

\begin{abstract}
OBJECTIVE Far-lateral or extreme-lateral approaches to the skull base allow access to the lateral and anterior portion of the lower posterior fossa and foramen magnum. These approaches include a certain extent of resection of the condyle, which potentially results in craniocervical junction instability. However, it is debated what extent of condyle resection is safe and at what extent of condyle resection an occipitocervical fusion should be recommended. The authors reviewed cases of condyle resection/destruction with regard to necessity of occipitocervical fusion.
\end{abstract}

METHODS The authors conducted a retrospective analysis of all patients in whom a far- or extreme-lateral approach including condyle resection of various extents was performed between January 2007 and December 2014.

RESULTS Twenty-one consecutive patients who had undergone a unilateral far- or extreme-lateral approach including condyle resection were identified. There were 10 male and 11 female patients with a median age of 61 years (range $22-83$ years). The extent of condyle resection was $25 \%$ or less in 15 cases, $50 \%$ in 1 case, and greater than $75 \%$ in 5 cases. None of the patients who underwent condyle resection of $50 \%$ or less was placed in a collar postoperatively or developed neck pain. Two of the patients with condyle resection of greater than $75 \%$ were placed in a semirigid collar for a period of 3 months postoperatively and remained free of pain after this period. At last follow-up none of the cases showed any clear sign of radiological or clinical instability.

CONCLUSIONS The unilateral resection or destruction of the condyle does not necessarily result in craniocervical instability. No evident instability was encountered even in the 5 patients who underwent removal of more than $75 \%$ of the condyle. The far- or extreme-lateral approach may be safer than generally accepted with regard to craniocervical instability as generally considered and may not compel fusion in all cases with condylar resection of more than $75 \%$.

http://thejns.org/doi/abs/10.3171/2015.5.JNS15176

KEY WORDS far-lateral approach; craniovertebral joint instability; occipitocervical fusion; condyle destruction; skull base

$\mathrm{T}$ HE far-lateral or extreme-lateral approaches to the skull base allow a wide exposure of the lower lateral and anterior portion of the posterior cranial fossa as well as the craniocervical junction. The key for optimal exposure of this area is the resection of a certain extent of the condyle and the jugular tubercle. Synonyms for far- or extreme-lateral approaches are therefore also transcondylar and transtubercular approaches. Drilling of these parts of the occipital bone widens the operative corridor and reduces the need for retraction of the cerebellum and the medulla oblongata. In the last few years, transcondylar approaches to the craniovertebral junction have been increasingly reported to reach a variety of lesions such as tumors, cysts, vascular malformations, and aneu- rysms. ${ }^{1,2,4,5,7,8,11-14}$ Surgically induced craniocervical junction instability, the main drawback of this approach, has been described. Clinical signs of craniocervical junction instability are incapacitating pain and neurological deficits caused by compression of the medulla. In these cases, occipitocervical fusion is required. However, loss of motion in the occiput-C1 and $\mathrm{C} 1-2$ segments results in significant disability and impairment in the patient's quality of life. The recommendation for an occipitocervical fusion has been based primarily on the extent of condyle resection. According to a biomechanical laboratory study, the risk for craniocervical junction instability increases with the degree of condyle loss. ${ }^{16}$ Based on other single-center experience, occipitocervical fusion was recommended for 
patients with condyle destruction or resection of $50 \% 13,16$ or $70 \% .{ }^{4}$ Having the disabling nature of an occipital fusion in mind, we follow a conservative approach at our institution. The indication for occipitocervical fusion was based on the clinical signs of craniocervical instability and not on radiological signs such as increased motion on flexion-extension radiographs or condyle loss on CT.

The aim of this study is to present our own experience with the far- or extreme-transcondylar approach in terms of the necessity of occipitocervical fusion.

\section{Methods}

We performed a retrospective review of patients who underwent surgical treatment for lesions at the craniocervical junction between January 2007 and December 2014 via a unilateral far-lateral or extended far-lateral approach that included condylar resection. Twenty-one consecutive patients were identified, and their data were retrospectively examined. Data were gathered through review of patients' case notes, relevant imaging, and electronic medical records. MRI studies including contrast-enhanced sequences were obtained in 20 cases. One patient had a cardiac pacemaker, which was incompatible with MRI. CT scans of the affected region and flexion-extension radiographs were obtained in all cases of condyle destruction or resection of $\geq 50 \%$ to better evaluate the extent of bone destruction or possible craniovertebral junction instability. Follow-up was performed at outpatient evaluation at 3 and 12 months and yearly thereafter for benign lesions and at 3-month intervals for malignant lesions. One patient had a neuroenteric cyst and therefore underwent only 1 followup visit 3 months postoperatively. Patients were evaluated pre- and postoperatively for neck pain, cervical mobility, and neurological deficits.

\section{Results}

There were 10 male and 11 female patients with a median age of 61 years (range 22-83 years). Lesions included 6 meningiomas, 3 glomus paragangliomas, 3 schwannomas, 2 metastases, 2 cholesteatomas, 1 primary adenoid carcinoma, 1 chondrosarcoma, 1 neurenteric cyst, 1 posterior inferior cerebellar artery aneurysm, and 1 condyle chondroma. The most common cause of presentation was cranial nerve palsy, which was seen in 13 cases $(62 \%)$ (Table 1). The mean follow-up duration was 27 months (range 3-84 months). Intraoperative monitoring, including somatosensory, motor, and acoustic evoked potentials, and facial and caudal cranial nerve monitoring, was performed in all cases.

The lesion dictates the extent of condyle drilling. For lesions located ventromedial to the brainstem and upper cervical spine and lesions of the jugular foramen, minimal condyle drilling was required. In the case of the patient with a posterior inferior cerebellar artery aneurysm, drilling of less than the posterior fourth of the condyle was sufficient to gain optimal exposure. In the case of a 22 -yearold man with a glomus paraganglioma, drilling up to the hypoglossal canal (50\% of the condyle) was needed. In all

TABLE 1. Patient characteristics

\begin{tabular}{|c|c|c|c|c|}
\hline Case No. & Age (yrs), Sex & Reason for Presentation & Pathology & Condylar Destruction/Resection \\
\hline 1 & $83, \mathrm{M}$ & $\mathrm{CM}$ & Foramen magnum meningioma & $<25 \%$ \\
\hline 2 & $44, \mathrm{~F}$ & CN XII palsy & Hypoglossal schwanomma & $>75 \%$ \\
\hline 3 & $66, M$ & Occlusive hydrocephalus & Foramen magnum meningioma & $<25 \%$ \\
\hline 4 & $44, \mathrm{M}$ & LCN palsy & Hypoglossal schwanomma & $>75 \%$ \\
\hline 5 & $22, \mathrm{M}$ & CN IX palsy & Glomus paraganglioma & $50 \%$ \\
\hline 6 & $60, F$ & LCN palsy & Petrous bone chondrosarcoma & $<25 \%$ \\
\hline 7 & $63, \mathrm{~F}$ & LCN palsy & Jugular foramen meningioma & $<25 \%$ \\
\hline 8 & $62, \mathrm{~F}$ & CN VIII palsy & Glomus paraganglioma & $<25 \%$ \\
\hline 9 & $38, F$ & Headache & Clival meningioma & $<25 \%$ \\
\hline 10 & $77, \mathrm{M}$ & CN VII \& VIII palsy & Prostate carcinoma metastasis & $>75 \%$ \\
\hline 11 & $75, \mathrm{~F}$ & CN VII palsy & Foramen magnum meningioma & $<25 \%$ \\
\hline 12 & $43, M$ & CN IX palsy & Glomus paraganglioma & $<25 \%$ \\
\hline 13 & $46, M$ & Headache & Petrous bone cholesteatoma & $<25 \%$ \\
\hline 14 & $34, F$ & Headache & Petrous bone cholesteatoma & $<25 \%$ \\
\hline 15 & $61, F$ & $\mathrm{CM}$ & Foramen magnum meningioma & $<25 \%$ \\
\hline 16 & $72, \mathrm{~F}$ & CN VIII palsy & CUP metastases & $>75 \%$ \\
\hline 17 & $66, M$ & $\mathrm{CM}$ & Neuroenteric cyst & $<25 \%$ \\
\hline 18 & $57, \mathrm{~F}$ & LCN palsy & Glossopharyngeal schwanomma & $<25 \%$ \\
\hline 19 & 69 & SAH & PICA aneurysm & $<25 \%$ \\
\hline 20 & $33, \mathrm{M}$ & LCN palsy & Primary adenoid carcinoma & $<25 \%$ \\
\hline 21 & $63, M$ & LCN palsy & Clival chondroma & $>75 \%$ \\
\hline
\end{tabular}

$\mathrm{CM}=$ cervical myelopathy; $\mathrm{CN}$ = cranial nerve; $\mathrm{CUP}$ = cancer of unknown origin; $\mathrm{LCN}=$ lower cranial nerve; $\mathrm{PICA}=$ posterior inferior cerebellar artery; $\mathrm{SAH}=$ subarachnoid hemorrhage. 
TABLE 2. Characteristics of patients with condylar destruction/resection of greater than $75 \%$

\begin{tabular}{|c|c|c|c|c|c|c|}
\hline $\begin{array}{l}\text { Case } \\
\text { No. }\end{array}$ & $\begin{array}{l}\text { Age (yrs), } \\
\text { Sex }\end{array}$ & Cause of Presentation & Pathology & $\begin{array}{l}\text { Neurological } \\
\text { Improvement }\end{array}$ & $\begin{array}{l}\text { Last Follow-Up } \\
\text { (mos) }\end{array}$ & $\begin{array}{c}\text { Postop Cervical } \\
\text { Collar }\end{array}$ \\
\hline 2 & $44, \mathrm{~F}$ & CN XII palsy & Hypoglossal schwanomma & No & 84 & None \\
\hline 4 & $44, \mathrm{M}$ & LCN palsy & Hypoglossal schwanomma & No & 69 & None \\
\hline 10 & $77, \mathrm{M}$ & CN VII \& VIII palsy & Prostate carcinoma metastasis & Partial & 33 & $3 \mathrm{mos}$ \\
\hline 16 & $72, \mathrm{~F}$ & CN VIII palsy & CUP metastases & Full & 6 & 3 mos \\
\hline 21 & $63, M$ & LCN palsy & Clival chondroma & Partial & 3 & None \\
\hline
\end{tabular}

5 patients with a postoperative resection of more than $75 \%$ of the occipital condyle, already preoperatively, the occipital condyle was partially destroyed by the underlying pathology. In these patients, the operative drilling itself uncovered the extradural tumor. The overall postoperative condyle resection was a combination of the preoperative destruction and intraoperative drilling of the occipital condyle. None of the 16 patients with condyle resection of $75 \%$ or less was placed in a collar postoperatively or developed neck pain or signs of brainstem compression. In the 5 patients with condyle resection or destruction of more than $75 \%$, only the 2 patients with malignant and rapid-growing tumors were placed in a semirigid collar for 3 months following surgery. For the 3 patients with benign and slow-growing lesions no postoperative collar was necessary (Table 2). All patients received nonsteroidal antiinflammatory agents for pain control in the acute postoperative phase. None of patients, regardless of the extent of condyle resection/destruction, needed specific long-term pain management.

\section{Illustrative Cases \\ Case 4}

A 44-year-old man presented with a 2-month history of progressive dysphagia and right-sided tongue atrophy.

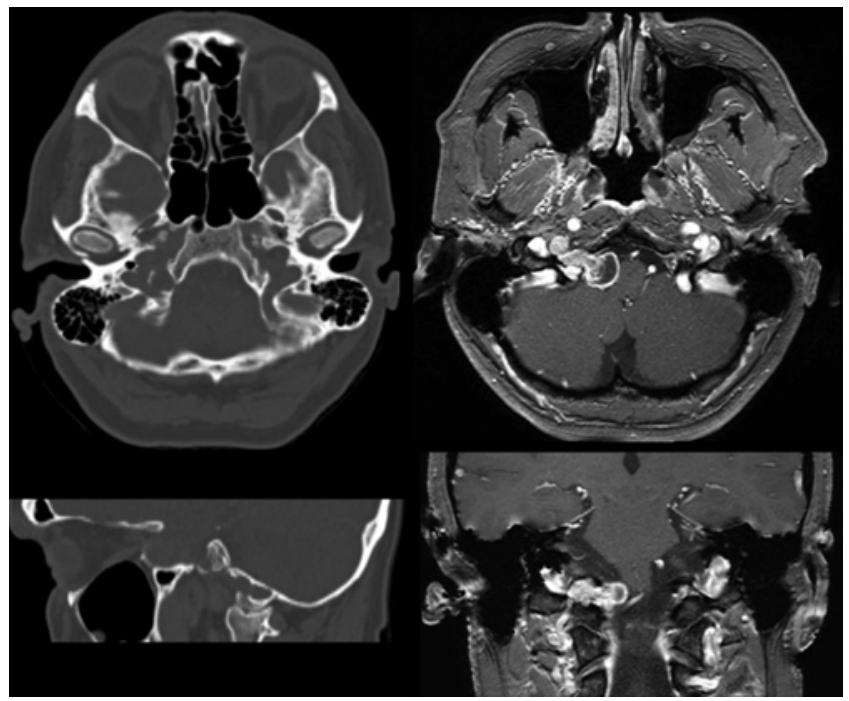

FIG. 1. Case 4. Preoperative neuroimages demonstrating a contrastenhancing intra-/extraforaminal lesion through the hypoglossal canal eroding much of the right condyle.
Neurological examination revealed nerve palsy of CNs X, $\mathrm{XI}$, and XII. MR and CT imaging demonstrated a contrastenhancing dumbbell-shaped lesion of the hypoglossal canal eroding most of the right condyle (Fig. 1). The patient underwent an extended far-lateral approach for resection of the hypoglossal tumor. The tumor was strongly adhesive to the pars nervosa of the jugular foramen. Therefore, subtotal resection was performed to minimize the risk of a new neurological deficit. Histopathological examination revealed a WHO Grade I schwannoma. The postoperative course was uneventful. Because the patient did not have any neck pain prior to or following surgery, we decided not to perform occipitocervical fusion. Nine months later, progression of the residual tumor was demonstrated on follow-up imaging. The operation was repeated, and a gross-total tumor resection was achieved (Fig. 2). At last follow-up (67 months) radiographs demonstrated no signs of instability (Fig. 3), and the patient had no neck pain or any new neurological deficits.

\section{Case 10}

A 77-year-old man with known prostate cancer with multiple skeletal metastases presented with a new onset of a right-sided House-Brackmann Grade III facial palsy and

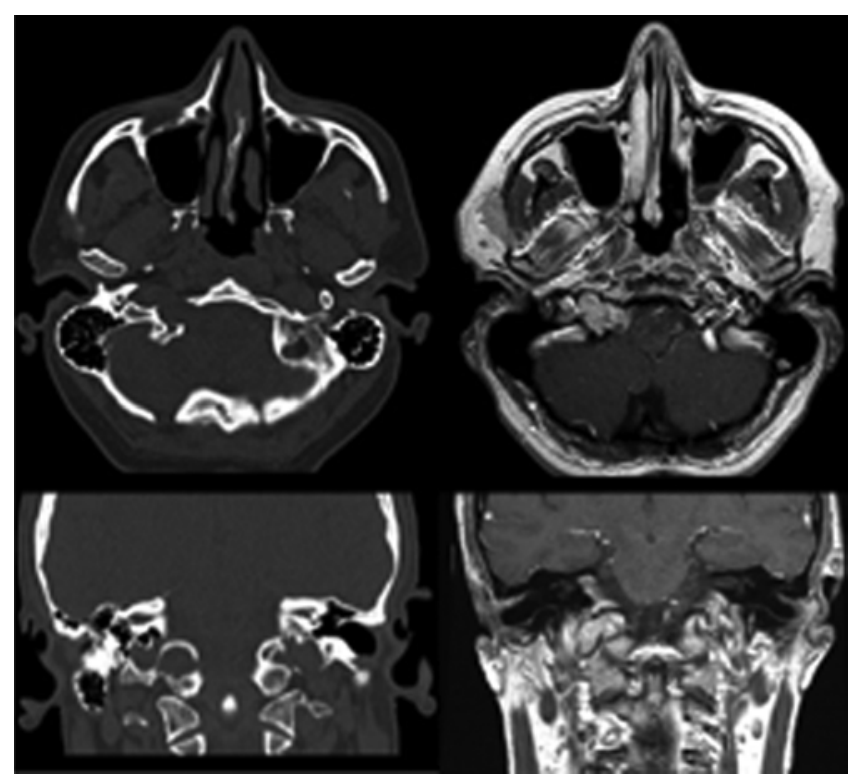

FIG. 2. Case 4. Postoperative neuroimages demonstrating a subtotal resection. 

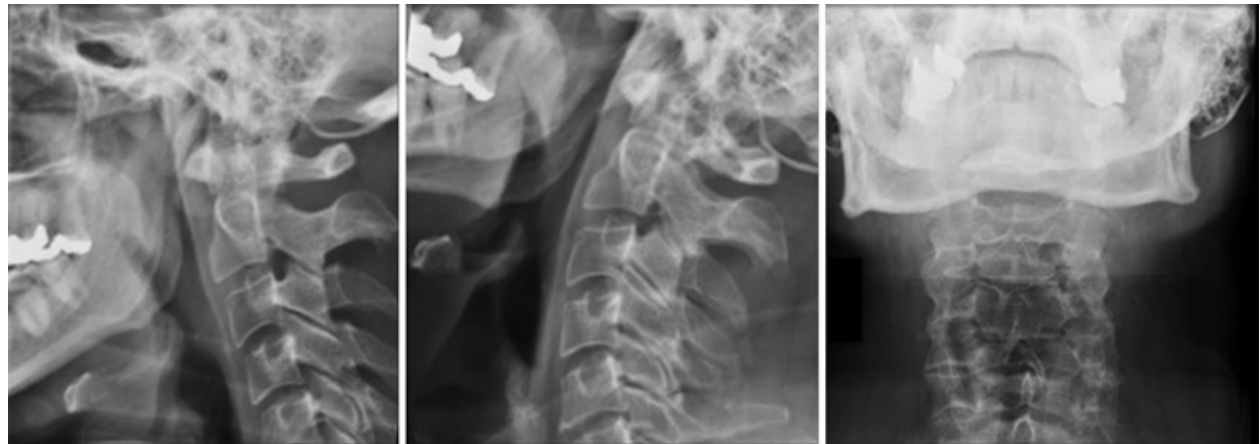

FIG. 3. Case 4. Static and flexion-extension radiographs obtained at the last follow-up (67 months) without any sign of axial instability.

hypacusis. MR and CT imaging demonstrated a large contrast-enhancing osteolytic lesion in the posterior fossa extending into petrous bone and condyle with displacement of the vertebral artery at C-1 (Fig. 4). He underwent an extended far-lateral approach, and subtotal resection was achieved (Fig. 5). Histopathological examination showed an adenocarcinoma of prostate origin. The postoperative course was uneventful. In order not to postpone adjuvant therapy, occipitocervical fusion was not performed and the patient was placed in a semirigid cervical collar postoperatively. The patient was successfully weaned from the cervical collar 3 months postoperatively. His facial palsy resolved completely, but his hypacusis did not improve. He developed further spinal metastases without neurological deficits and was managed conservatively. At last follow-up (21 months) radiographs demonstrated axial misalignment

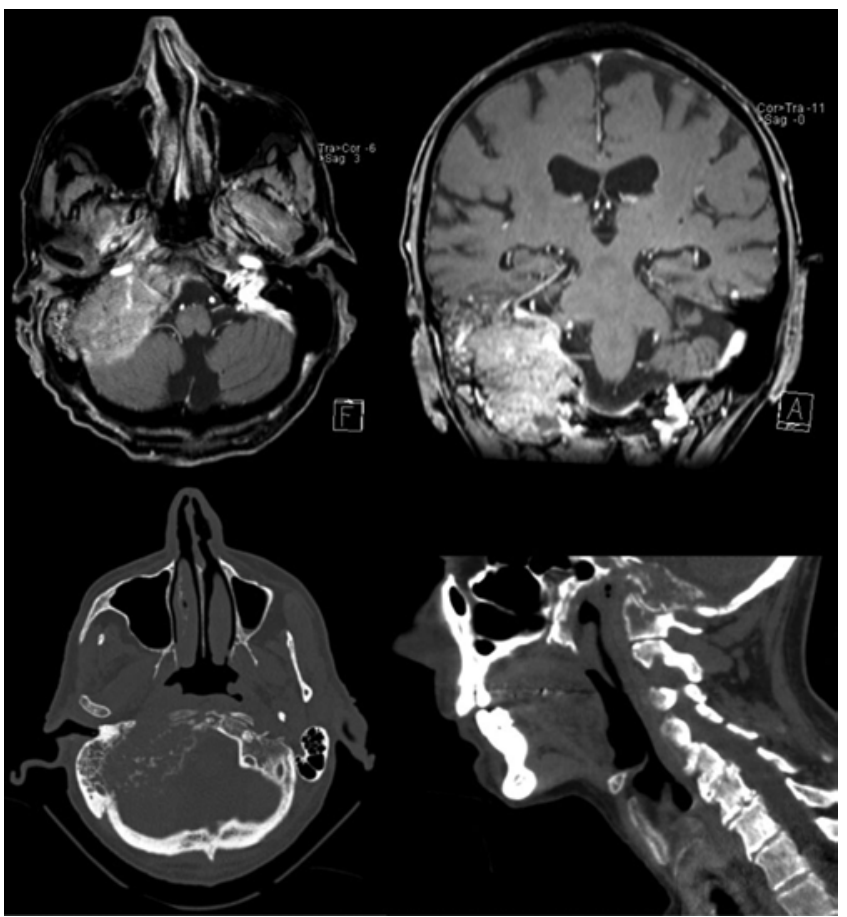

FIG. 4. Case 10. Preoperative neuroimages showing a large contrast enhancing osteolytic lesion of the posterior fossa extending into petrous bone and condyle with displacement of the vertebral artery at C-1. on the anteroposterior radiographs but no clear signs of instability on the flexion-extension radiographs (Fig. 6). The patient had no neck pain or any signs of medulla oblongata compression.

\section{Discussion}

Far-lateral and extreme-lateral approaches allow an optimized exposure of the inferior portion of the clivus, the intradural vertebral artery, and vertebrobasilar junction, as well as the medulla oblongata. According to Bertalanffy and Seeger, who first described this approach, a limited resection of the condyle is needed to expose the aforementioned areas. ${ }^{5}$ In a recent morphometric analysis, the jugular tubercle and not the condyle as part of the atlantooccipital joint was found as the obstacle in the surgical corridor in this approach. ${ }^{10}$ Depending on the location of the pathology (i.e., intradural, intraextradural, or purely extradural), and the amount of bone destruction, infiltration, or displacement of adjacent structures, a tailoring of the approach may include more or less resection of the occipitoatlantal joint. This may lead to a craniocervical instability, which is difficult to define. Clinical instability has

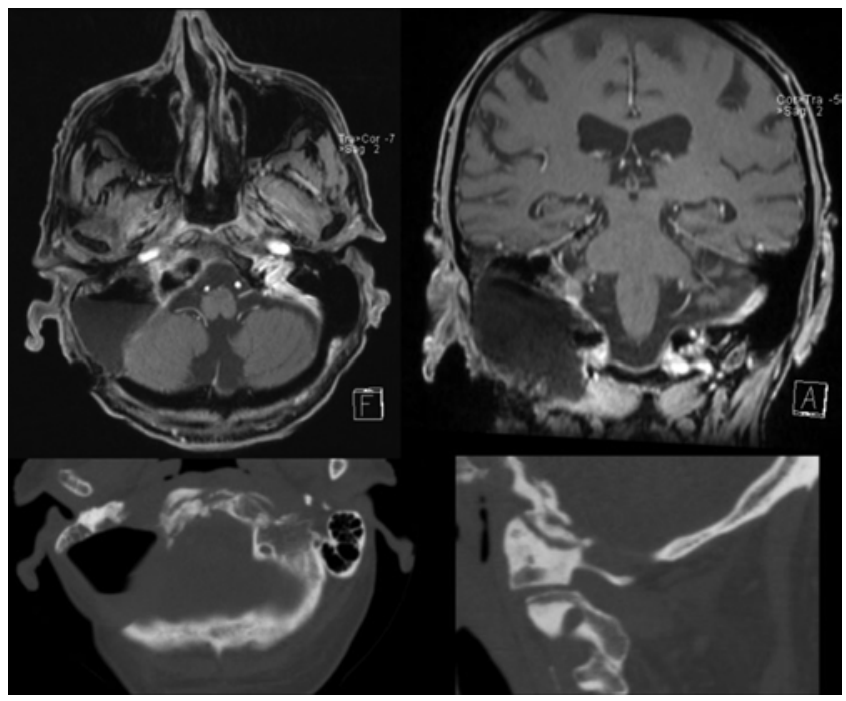

FIG. 5. Case 10. Postoperative neuroimages demonstrating resection of the lesion. 

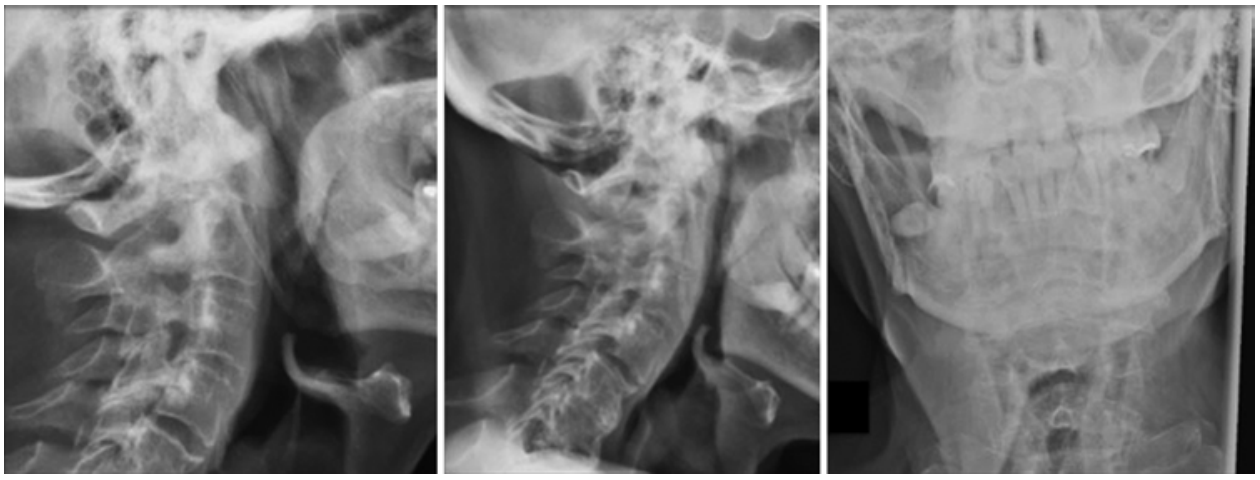

FIG. 6. Case 10. Static and flexion-extension radiographs obtained at last follow-up (33 months), illustrating head tilting to the left without clear axial instability.

been defined as the "loss of the ability of the spine under physiological loads to maintain its pattern of displacement so that there is no initial or additional neurological deficit, no major deformity, and no incapacitating pain." ${ }^{17}$ In our practice, this definition is the principle for the recommendation whether to perform fusion or not. In another definition for spine instability, acute instability is divided into "overt" and "limited." 3 For the craniocervical junction, these 2 categories may be divided by the morphological resection/destruction of the atlantooccipital joint or nonphysiological motion on flexion-extension radiographs. ${ }^{13,16}$

Recommendations for occipitocervical fusion following lateral approaches have been based on biomechanical studies and a few single-center experiences. In a laboratory setting, the effects of staged condylectomy on the range of motion at occiput- $\mathrm{Cl}$ and $\mathrm{Cl}-2$ articulation in 6 human cadaver specimens was studied.$^{16}$ An incremental $25 \%$ removal of a unilateral condyle from the medial to the lateral side was performed. The range of motion at the occiput-C1 articulation showed statistically significant hypermobility for all motion following $50 \%$ resection, and frank instability was measured after $75 \%$ resection. Based on their findings, the authors recommended occipitocervical fusion if $\geq 50 \%$ resection of the condyle is performed. Another study reported the experience in a retrospective review of 27 patients in whom an extreme-lateral transcondylar approach was performed. ${ }^{4}$ The indication for occipitocervical fusion was one or more of the following: 1) radiological instability on flexion-extension radiographs, 2) clinical instability defined by the presence of a painful head tilt, and 3) complete resection of the condyle. The third criterion was based on the experience in 6 patients with complete condyle resection because of the high incidence of painful head tilt as well as radiological instability in those patients. Eight patients required occipitocervical fusion and all had more than $70 \%$ resection of their condyle. None of the patients with condyle resection of less than $70 \%$ required occipitocervical fusion. Based on their experience, the authors concluded that most patients with less than $70 \%$ resection of the condyle would not require fusion and patients following resection of more than $70 \%$ are recommended for occipitocervical fusion. However, the authors also stated that the recommendation is based on a limited number of patients.
Our data, although limited by the small number of patients and in some cases with short-term follow-up periods, provide a more conservative basis in decision making with regard to occipitocervical fusion for patients following far-lateral approaches. None of the patients in this study required occipitocervical fusion. None of the patients with $50 \%$ or less resection of the condyle were placed a rigid cervical collar postoperatively, and none developed neck pain or signs of brainstem compression. Five patients had condyle destruction of more than $75 \%$ due to the osteodestructive nature of the tumor (Cases 10, 16, and 21) or due to compressive erosion of the bone (Cases 2 and 4). Of those patients only 1 (Case 16) presented with slight intermittent neck pain that evolved into neck "discomfort" after 3 months. Even for those 5 patients with preoperative destruction of the condyle of more than $75 \%$, occipitocervical fusion was not deemed necessary because these patients did not have any signs of clinical instability and we were therefore encouraged not to perform fusion. We found that only for those patients with rapid destruction of the condyle was a postoperative rigid collar necessary. For those with slow-growing lesions and intact ligaments of the occiput- $\mathrm{Cl}$ and $\mathrm{Cl}-2$ articulation, postoperative collar fixation seemed to be unnecessary.

Obviously, with the limited number of patients in our series we were not able to fully explore and explain why these patients did not develop clinically evident instability. However, it is well established that both motion and stability of the craniocervical junction are determined by the unique bone and ligament configurations., ${ }^{915}$ Because there are no intervertebral discs and because the articular facets are aligned horizontally, stability is primarily derived from the ligaments and membranes in this region and not by the bone structures. ${ }^{6}$ Therefore, recommendations for occipitocervical fusion should not be based solely on the extent of bone destruction but have to take into consideration the integrity of the ligament in this region.

To date, there are not sufficient data available for skull base or spine surgeons to make a definitive recommendation, based on CT morphometric evaluation of the condyle resection/destruction, as to which patients should undergo occipitocervical fusion following a lateral approach including condyle loss. Plain radiographs do not provide reliable visualization of the atlantooccipital joint that allows sub- 
luxation or rotatory instability to be evaluated. Therefore, indications for occipitocervical fusion should not be based upon plain radiographs alone. A prophylactic occipitocervical fusion for the possibility that a glacial instability of the atlantooccipital joint could develop and eventually progress to overt instability ${ }^{13}$ years ahead is not recommended, especially in patients with metastatic disease and a limited overall survival.

\section{Conclusions}

The unilateral resection or destruction of the condyle does not necessarily result in craniocervical instability. Even in the 5 cases with removal of $>75 \%$ of the condyle without significant destruction of the ligaments of the joint, no evident instability was encountered. The indication for craniocervical fusion should be based on clinical signs such as pain in head tilt or neurological deficits due to compression of the medulla. The far-lateral or extremelateral approach may be safer with regard to craniocervical instability as generally considered and may not compel fusion in all cases with condylar resection of more than $75 \%$.

\section{References}

1. Abla AA, Turner JD, Mitha AP, Lekovic G, Spetzler RF: Surgical approaches to brainstem cavernous malformations. Neurosurg Focus 29(3):E8, 2010

2. al-Mefty O, Borba LA, Aoki N, Angtuaco E, Pait TG: The transcondylar approach to extradural nonneoplastic lesions of the craniovertebral junction. J Neurosurg 84:1-6, 1996

3. Benzel EC: Stability and instability of the spine, in Benzel EC (ed): Biomechanics of Spine Stabilization: Principles and Clinical Practice, ed 1. New York: McGraw-Hill, 1995, pp 25-38

4. Bejjani GK, Sekhar LN, Riedel CJ: Occipitocervical fusion following the extreme lateral transcondylar approach. Surg Neurol 54:109-116, 2000

5. Bertalanffy H, Seeger W: The dorsolateral, suboccipital, transcondylar approach to the lower clivus and anterior portion of the craniocervical junction. Neurosurgery 29:815821,1991

6. Crisco JJ III, Oda T, Panjabi MM, Bueff HU, Dvorák J, Grob D: Transections of the $\mathrm{C} 1-\mathrm{C} 2$ joint capsular ligaments in the cadaveric spine. Spine (Phila Pa 1976) 16 (10 Suppl):S474S479, 1991

7. Liu JK, Couldwell WT: Far-lateral transcondylar approach: surgical technique and its application in neurenteric cysts of the cervicomedullary junction. Report of two cases. Neurosurg Focus 19(2):E9, 2005

8. Matsushima T, Matsukado K, Natori Y, Inamura T, Hitotsumatsu T, Fukui M: Surgery on a saccular vertebral artery- posterior inferior cerebellar artery aneurysm via the transcondylar fossa (supracondylar transjugular tubercle) approach or the transcondylar approach: surgical results and indications for using two different lateral skull base approaches. J Neurosurg 95:268-274, 2001

9. Menezes AH, Traynelis VC: Anatomy and biomechanics of normal craniovertebral junction (a) and biomechanics of stabilization (b). Childs Nerv Syst 24:1091-1100, 2008

10. Mintelis A, Sameshima T, Bulsara KR, Gray L, Friedman AH, Fukushima T: Jugular tubercle: Morphometric analysis and surgical significance. J Neurosurg 105:753-757, 2006

11. Pirotte BJ, Brotchi J, DeWitte O: Management of anterolateral foramen magnum meningiomas: surgical vs conservative decision making. Neurosurgery 67 (3 Suppl Operative):ons 58-ons70, 2010

12. Sen C, Shrivastava R, Anwar S, Triana A: Lateral transcondylar approach for tumors at the anterior aspect of the craniovertebral junction. Neurosurgery 66 (3 Suppl):104-112, 2010

13. Shin H, Barrenechea IJ, Lesser J, Sen C, Perin NI: Occipitocervical fusion after resection of craniovertebral junction tumors. J Neurosurg Spine 4:137-144, 2006

14. Spetzler RF, Grahm TW: The far-lateral approach to the anterior clivus and the upper cervical region. BNI Q 6:35-38, 1990

15. Steinmetz MP, Mroz TE, Benzel EC: Craniovertebral junction: biomechanical considerations. Neurosurgery $66(3$ Suppl):7-12, 2010

16. Vishteh AG, Crawford NR, Melton MS, Spetzler RF, Sonntag VK, Dickman CA: Stability of the craniovertebral junction after unilateral occipital condyle resection: a biomechanical study. J Neurosurg 90 (1 Suppl):91-98, 1999

17. White AA III, Panjabi MM: The problem of clinical instability of the human spine: a systematic approach, in White AA III, Panjabi MM (eds): Clinical Biomechanics of the Spine. Philadelphia: J.B. Lippincott, 1990, pp 277-378

\section{Disclosure}

The authors report no conflict of interest concerning the materials or methods used in this study or the findings specified in this paper.

\section{Author Contributions}

Conception and design: Shiban, Lehmberg. Acquisition of data: Shiban, Török, Wostrack. Analysis and interpretation of data: Shiban, Lehmberg. Drafting the article: Shiban. Critically revising the article: Lehmberg. Reviewed submitted version of manuscript: Meyer, Lehmberg. Study supervision: Meyer, Lehmberg.

\section{Correspondence}

Ehab Shiban, Department of Neurosurgery, Klinikum rechts der Isar, Technische Universität München, Ismaninger Str. 22, 81675 Munich, Germany.email: ehab.shiban@lrz.tum.de. 